\title{
Nosocomial Pneumonia
}

National Cancer Institute

\section{Source}

National Cancer Institute. Nosocomial Pneumonia. NCI Thesaurus. Code C115297.

Pneumonia acquired during a hospital stay. 